$\mathbf{R}_{\text {ESEARCH }} \mathbf{P}_{\text {APER }} \longrightarrow$ FOOD SCIENCE

ISSN-2230-9403 - Visit us :

www.researchjournal.co.in

Volume 9 | Issue 1 | April, 2018 | 106-111

DOI : $10.15740 / \mathrm{HAS} / \mathrm{FSRJ} / 9.1 / 106-111$

\title{
Breakfast consumption pattern and nutritional status of adolescent girls
}

\author{
Divya Jain and Kiran Grover
}

To assess the breakfast consumption pattern and nutritional status, a total of 500 adolescent girls in the age group of 1618 years were selected randomly from rural and urban government schools of Ludhiana district. An interview schedule was used to assess their meal pattern, frequency of breakfast consumption and reasons behind their skipping of breakfast. Their height and weight was measured and BMI was also calculated. The results revealed that the prevalence of breakfast consumption on daily basis was higher among urban adolescent girls (51\%) than rural (46\%) and frequency decreased with increase in age. The major reasons behind skipping of breakfast were lack of appetite (37\%), time (28\%) and family meal pattern $(17 \%)$. A higher percentage of rural adolescent girls were found to be underweight as compared to their urban counterparts but out of underweight category more of urban adolescent girls were found to be severely thin.

Key Words : Breakfast consumption pattern, Appetite, Adolescence, Meal pattern, Breakfast skipping, Underweight

How to cite this article : Jain, Divya and Grover, Kiran (2018). Breakfast consumption pattern and nutritional status of adolescent girls. Food Sci. Res. J., 9(1): 106-111, DOI : 10.15740/HAS/FSRJ/9.1/106-111. 